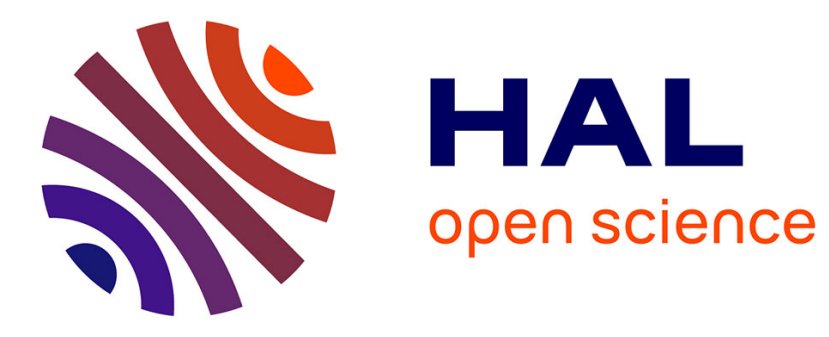

\title{
Quantum-dash mode-locked laser source for wavelength-tunable 56 Gbit/s DQPSK
}

Yousra Ben M'Sallem, Quang Trung Le, Laurent Bramerie, Quoc Thai

Nguyen, Eric Borgne, Pascal Besnard, Sophie La Rochelle, Leslie A. Rusch, Jean-Claude Simon

\section{To cite this version:}

Yousra Ben M'Sallem, Quang Trung Le, Laurent Bramerie, Quoc Thai Nguyen, Eric Borgne, et al.. Quantum-dash mode-locked laser source for wavelength-tunable 56 Gbit/s DQPSK. 36th European Conference on Optical Communication (ECOC 2010), Sep 2010, Turin, Italy. pp.Mo.1.F.4, 10.1109/ECOC.2010.5621590 . hal-00569382

\section{HAL Id: hal-00569382 \\ https://hal.science/hal-00569382}

Submitted on 24 Feb 2011

HAL is a multi-disciplinary open access archive for the deposit and dissemination of scientific research documents, whether they are published or not. The documents may come from teaching and research institutions in France or abroad, or from public or private research centers.
L'archive ouverte pluridisciplinaire HAL, est destinée au dépôt et à la diffusion de documents scientifiques de niveau recherche, publiés ou non, émanant des établissements d'enseignement et de recherche français ou étrangers, des laboratoires publics ou privés. 


\title{
Quantum-Dash Mode-Locked Laser Source for Wavelength-Tunable 56 Gbit/s DQPSK
}

\author{
Yousra Ben M'Sallem ${ }^{(1,2)}$, Quang Trung Le ${ }^{(1)}$, Laurent Bramerie ${ }^{(1)}$, Quoc-Thai Nguyen ${ }^{(1)}$, Eric Borgne ${ }^{(1)}$, \\ Pascal Besnard ${ }^{(1)}$, Sophie LaRochelle ${ }^{(2)}$, Leslie A. Rusch ${ }^{(2)}$, Jean-Claude Simon ${ }^{(1)}$ \\ (1) Université Européenne de Bretagne (UEB), CNRS-Foton laboratory (UMR 6082)/Université de \\ Rennes 1, Enssat, BP 80518, 22305 Lannion Cedex, France, quang-trung.le@enssat.fr \\ (2) Université Laval, ECE Dept., COPL, Québec, Canada, rusch@gel.ulaval.ca
}

\begin{abstract}
We investigate wavelength tunable $56 \mathrm{Gbit/s}$ DQPSK systems using comb generation in a quantum-dash mode-locked laser. Relative intensity noise and bit error rate is measured for each mode. Error-free operation is obtained over 9 WDM channels with $100 \mathrm{GHz}$ spacing.
\end{abstract}

\section{Introduction}

Since the phenomenal traffic growth of the Internet, data traffic has rapidly overtaken voice as the dominant information type transported by today's high speed communication networks. The next generation of optical networks requires efficient densely packed WDM channels to transmit massive amounts of information. An important challenge is the cost and the wavelength versatility of WDM transmitters.

WDM transmission using comb generation in a mode-locked laser (MLL) has been proposed as a cost-effective solution. The multiple frequencies (modes) of the MLLs offer several advantages compared to sets of single mode distributed feedback (DFB) lasers: fixed channel spacing set by the MLL mode spacing, reduced channel crosstalk due to the coherence of the MLL modes, etc. ${ }^{1}$ In addition, no individual channel frequency control is needed.

Optical frequency combs have been demonstrated using different configurations based on mode locked lasers. Examples include amplitude or frequency modulated mode-locked lasers, e.g., Er:Yb:glass laser oscillators ${ }^{2}$, fibre ring lasers ${ }^{3}$ or mode-locked semiconductor lasers ${ }^{4}$. Semiconductor lasers consume significantly less power as no pump diode laser is required. Recently, semiconductor quantum-dot or quantum-dash mode-locked lasers have been heavily investigated owing to remarkable properties, including low-noise, high thermal stability, and a broad gain spectrum ${ }^{5}$. They have been examined as particularly attractive sources for wavelength division multiplexing (WDM) using on-off keying $(\mathrm{OOK})^{6}$.

Phase-shift keying (PSK) has recently emerged as an alternative to conventional OOK modulation allowing for much higher spectral efficiencies. Despite their relatively complex transmitter and receiver setups, PSK is a strong candidate for high data-rate and spectrally efficient DWDM systems ${ }^{7}$. In this paper, we demonstrate for the first time that a quantumdash mode-locked laser (QD-MLL) can be used as multi-wavelength laser for 56 Gbit/s DQPSK transmission. We demonstrate that relative intensity noise (RIN) and phase noise over all modes are compatible with PSK modulation. We quantify DQPSK performance via bit error rate (BER) measurements and compare performance to that of an external cavity laser (ECL) source.

\section{QD-MLL characterisation}

The laser is fabricated with an active core consisting of 6 InAs-based QD layers. A cavity length of $420 \mu \mathrm{m}$ yields a mode spacing of $100 \mathrm{GHz}$; the device structure was reported in [6]. The optical spectrum of the laser is given in Fig. 1. Due to mode-locking, a wide spectrum is observed. The $3 \mathrm{~dB}$ optical bandwidth is about $8 \mathrm{~nm}$, covering ten optical modes.

Fig. 2 shows the RIN measurement results of 1) a commercial ECL, 2) all QD-MLL modes taken together, and 3) each filtered QD-MLL mode (from $1548.3 \mathrm{~nm}$ to $1555.6 \mathrm{~nm}$ ). Generally, the QD lasers have low intensity noise thanks to low amplified spontaneous emission $(A S E)^{5}$. The RIN of the total of all modes is even lower than that of a commercial ECL. However,

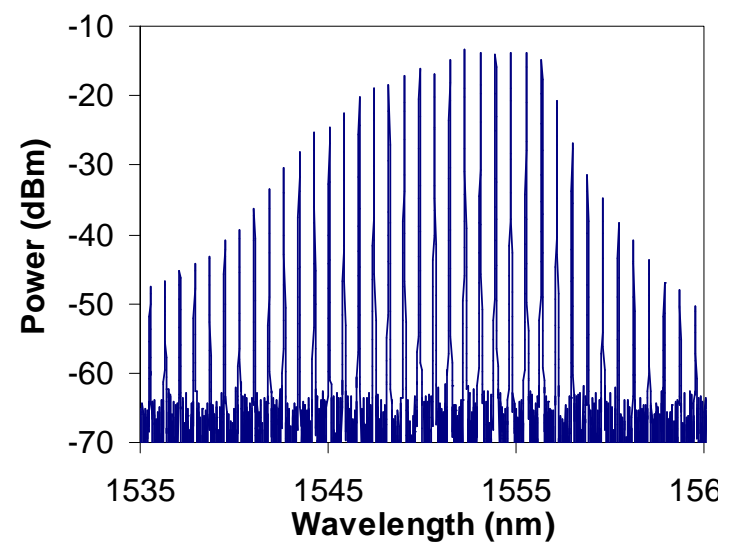

Fig. 1: Optical spectrum of the QD-MLL. 


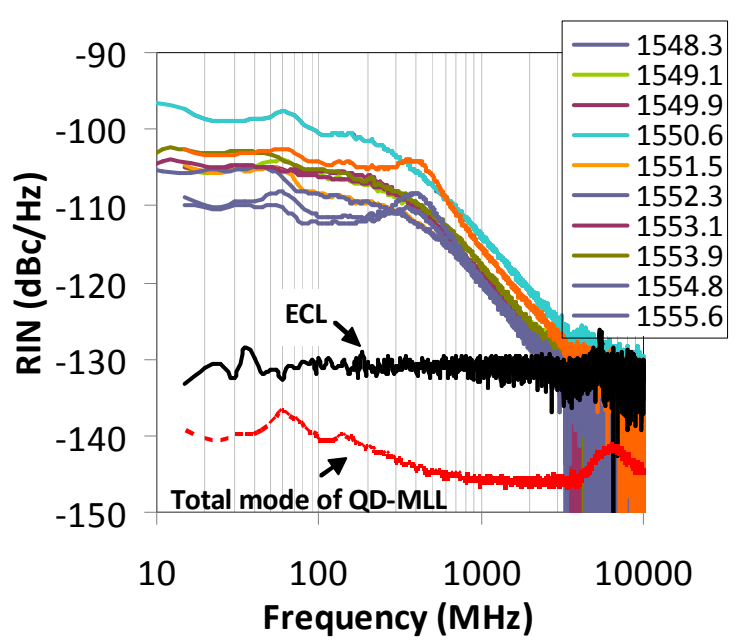

Fig. 2: Relative intensity noise (RIN).

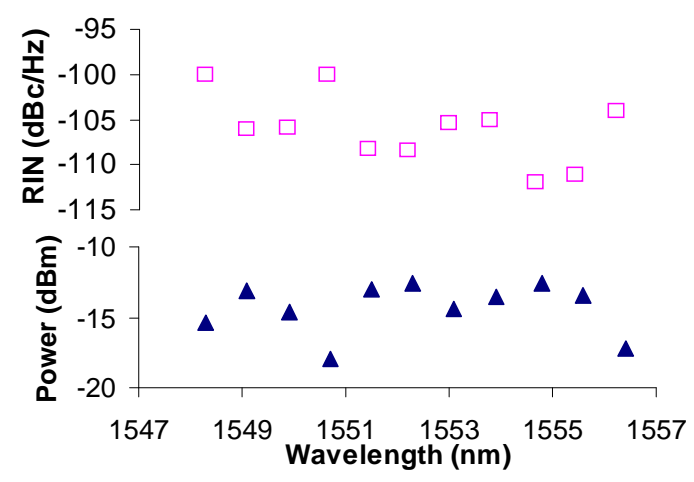

Fig. 3: Power level and RIN of each DQPSK QDMLL channel.

when using a QD-MLL wavelength comb as a WDM source, the RIN increases for each filtered mode due to mode partition noise ${ }^{8}$. As shown in Fig. 2, the RIN floor of one filtered mode can be as high as $-100 \mathrm{dBc} / \mathrm{Hz}$ for frequencies below $500 \mathrm{MHz}$, decreasing to $-130 \mathrm{dBc} / \mathrm{Hz}$ at $10 \mathrm{GHz}$ for the worst case observed. RIN is much higher than that of a commercial ECL (see Fig. 2).

Fig. 3 summarizes the RIN (at $100 \mathrm{MHz}$ ) and power level of each QD-MLL mode examined. Not surprisingly, the RIN of the non-dominant modes are strong compared to the QD-MLL dominant modes. In the next section we assess the impact of this higher RIN level on BER performance for DQPSK.

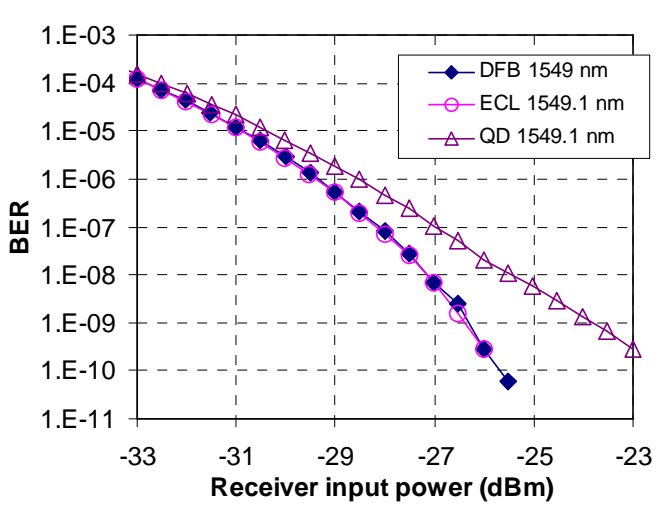

Fig. 5: Bit error rate vs. receiver input power.

\section{Experimental setup}

The experimental setup (Fig. 4) consists of a $56 \mathrm{Gbit} / \mathrm{s}$ DQPSK transmitter and receiver. A $100 \mathrm{GHz}$ quantum-dash Fabry-Perot modelocked laser source is used at the transmitter. The output of the laser passes through an optical isolator and then an arrayed waveguide grating (AWG) wavelength demultiplexer (for this experiment we use a tunable filter).

The selected lasing mode is amplified using an EDFA and externally modulated using a DQPSK, LiNbO3 Mach-Zehnder interferometer (MZI). With the test equipment available, we generate two $2^{9}-1$ pseudo random binary sequences (PRBS) delayed by 256 bits to decorrelate them. At the receiver the signal is preamplified, filtered and demodulated with delay interferometers (DLI). The DIs and balanced detectors convert the optical phase modulation into intensity modulation. The $28 \mathrm{Gbit} / \mathrm{s}$ bit stream passes through a 1:4 electronic demultiplexing stage; the $7 \mathrm{Gbit} / \mathrm{s}$ streams are sent to the error detector. The experimental test bed was implemented on the Persyst platform at Foton laboratory.

\section{Experimental results}

Results of DQPSK back-to-back measurements are shown in Fig. 5. For reference, the curve with square markers indicates BER vs. receiver input power for a DFB; BER is $10^{-9}$ at $-26 \mathrm{dBm}$. $B E R$ for an ECL source is reported with circle markers. Using one mode of the QD-MLL as a source yields BER reported with triangle mark-

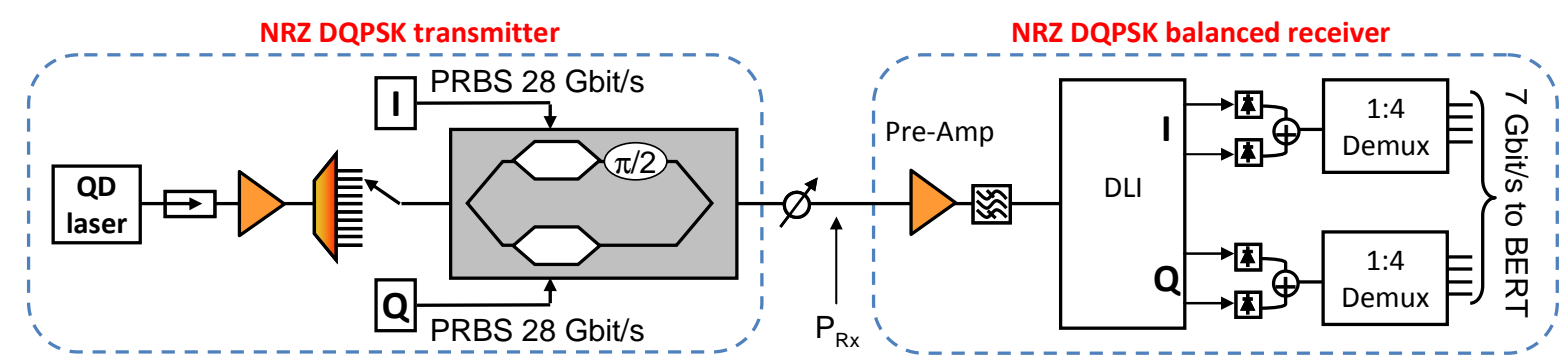

Fig. 4: Experimental setup. 


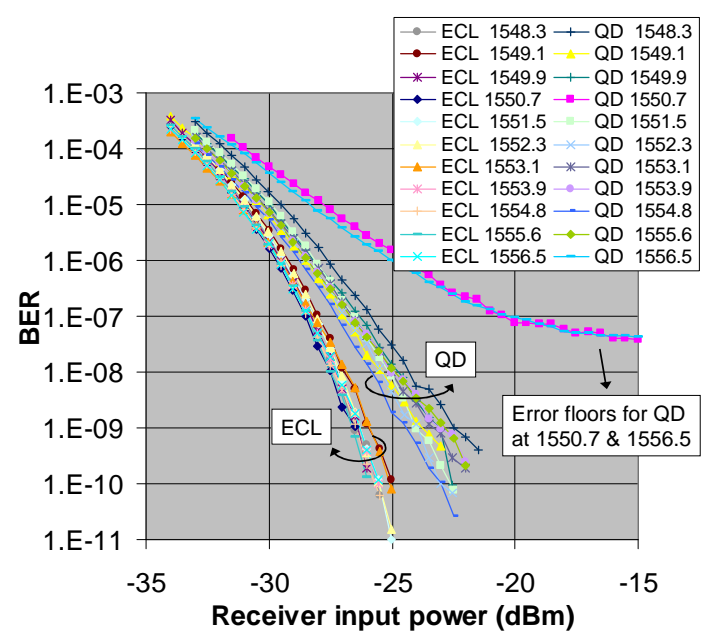

Fig. 6: Bit error rate vs. receiver input power for 11 ECL and QD-MLL channels.

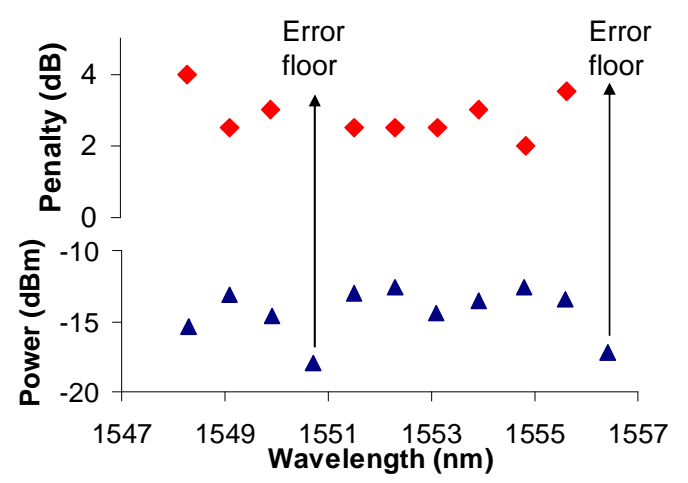

Fig. 7: Power level and penalty $\left(B E R=10^{-9}\right)$ of each DQPSK QD-MLL channel.

ers. All sources were centred at $1549 \mathrm{~nm}$. The $E C L$ and DFB give nearly identical BER. The QD-MLL has a power penalty of $2.5 \mathrm{~dB}$ at $10^{-9}$ compared to the DFB and ECL, yet nonetheless is error-free $\left(B E R<10^{-9}\right)$. This penalty is due to high RIN when filtering the QD-MLL to isolate one mode as discussed in the previous section.

The performance of our system is evaluated for each mode of the QD-MLL. For each wavelength, the DQPSK system is first optimised using the wavelength-adjustable ECL source. Next each mode of the QD-MLL is isolated in turn, and BER measurements are compared for ECL and QD-MLL, see Fig. 6. Results show that the DQPSK performance for the QD-MLL is as stable as the tuned ECL over the entire $8 \mathrm{~nm}$ range, from $1548.3 \mathrm{~nm}$ to $1556.4 \mathrm{~nm}$, covering 11 WDM channels with $100 \mathrm{GHz}$ spacing. The receiver sensitivity of the system using $E C L$ varies between $-26 \mathrm{dBm}$ and $-26.5 \mathrm{dBm}$ in this wavelength range. When the QD-MLL is used, error-free performance is obtained over nine channels. Error floors at BER of $4 \times 10^{-8}$ occur with two channels (1550.7 nm and $1556.5 \mathrm{~nm}$ ). This is to be expected given the RIN and power level of those modes.

Finally, Fig. 7 shows the power penalty (BER of $10^{-9}$ ) of DQPSK signals using each QD-MLL mode. Power penalty from $2 \mathrm{~dB}$ to $4 \mathrm{~dB}$ is obtained over nine WDM channels. For the weak modes, the power penalty rapidly increases. Not surprisingly, the fluctuations in non-dominant modes are strong compared to that of the dominant modes.

\section{Conclusions}

We proposed and experimentally demonstrated for the first time the feasibility of a cost-effective, multi- wavelength seeding source based on QDMLL for high speed and spectral efficient WDM systems using DQPSK modulation at $56 \mathrm{Gbit} / \mathrm{s}$. We reported error-free signal operation over nine WDM channels with $100 \mathrm{GHz}$ spacing. Therefore, this strategy is viable solution for future high bit rate optical communications networks.

\section{Acknowledgements}

This work was supported by the French National projects TELDOT and PERSYST $\|$ and by Québec's Regroupement Stratégique Centre for Advanced Systems and Technologies in Communications (SYTACom). The authors would like to thank A. Shen and G.-H. Duan from Alcatel-Thales III-V Lab for the laser fabrication, and P. Chanclou from Orange Lab for lending the RIN measurement equipment.

\section{References}

1 T. Healy, et al., Proc. ECOC'07,PD 1.9 (2007). 2 S.C. Zeller et al., Proc. CLEO'05, 221 (2005).

3 S. Yamashita et al., Phot. Tech. Lett., 10, 796 (1998).

4 A. Gubenko et al., Electron. Lett., 43, 1430 (2007).

5 F. Lelarge et al., J. Selected Topics in Quan. Elec., 13, 111 (2007).

6 A. Akrout et al., Proc. ECOC'08, Th3.D.4 (2008).

7 C. Xu, et al., Photon. Technol. Lett., 15, 617 (2003).

8 Petermann, Laser diode modulation and noise, Kluwer Academic Publishers (1991). 